\title{
[ I16]
}

\section{IX.}

Einige electrifche Bemerkungen.

(Aus einem Briefe des Herrn L. A. v. Arnim.) Halilane's Erklärung des Blitzes als eines Entlactungsfunkens, (Annalen der $P h y /\{k, V, 115$, ) ift fo natürlich, clafs er clen meiften einfallen mufs. ") Aber eben defswegen glaube ich, dafs der gerijhnliche Rath der Phyfiker für Furchtfame, fich zu ifoliren, zwar die Furcht, aber nicht die Gefahr ableiten möchte. Nur bei dem Uebergange durch Nicht - Leiter zeight fich der Blitz zerftürend; cin mit Netall hefchlagenes Zimmer würde laher ungleich zweckmalsiger feyn. Sie werden fich auch des Falles erinnern, ivo die goldenen Leifrea im Zimmer eine ganze Gefelllchaft gegen alle Gefahr fchut 2 en. Haldane's Erklärling über das Einfchlagen des Blitzes in Hüufer mit Gewițerableitern, fcheint mir niclut wahrfcheinlich. Der einzelne Funken, deran einer Flafrhe mit zerfchnittenem Stanniol zu dern einzelnen Stanniolftïckchen übergeht, kann kein Metall fchmelzen, wenn auch die ganze Ladung es thut, eben fo wenig fcheint der geringe Funken, der dem Haufe das electrifche Gleirhgewicht wiedergiebt, die mächtigen W:rkungen des ganzen

*) Vers!riche meine Theorie der electrifchen Erfolciumasen, S. gr.

A. 


\section{$\left[\begin{array}{lll}1 & 1 & 17\end{array}\right]$}

Blitzes hervorbringen zu künnen. Sollten nicht zurvesleu diefe Hlitzableiter an der Erde ifulirt gewefen ic $y n$, fo dafs der Blitz an einem Theile des Hutfes eine bifiere Haluleitung gefunden? Bei den glcichreeiligen Blitzeinfchlïgeil an .zwei verfühedenea Orien fcheint wabrfcheinlich etwas den ähnlich vorzugehn, was Aldinis. (Annalen der Phy/ik, IV, S. 420,) an halbbelegten Flafchen beobachtete. Wenn eins der beillen Häuler, Band $\boldsymbol{v}$, Taf. Ill, Fig. 2, dort clurch eine Wolke pofitiv electrifirt wird, fo wird das andere negativ, und electrifirt die über ihm fiehende Wolkenfchicht pofitiv; entladen fich'jene, fo entladet fich auch diele. Solche abrechfelnde pofitive und negative Zonen der Erile fcheint auch der Wechfel des Electrometers zwilchen politirer und negativer Electricität auszudriicken, (Amalen der Phyfik, III, $82 ;$ ) fo wie (las ür:iiche Einfchlagen der Gewitter ${ }^{*}$ ) lich fetr. wahrfcheinlich aus der Leitungsfühigkeit des. - Bodlens, und daher entftehenden Geneigtheit zu diefer Vertheilung erklären !älst.

Dals der electrifche Funken auf die Salzfüure ebenfalls feine Verwandtfebaft aufhebende liraft betwielen, (Ann. der Phyfik, V, 45.9.) war mir nicht unerwartet; das Licht \{chien das fchon lange

*) So erzühlt Maffei deilla formazione de Fulmini, Vernua 1747 , Lett. prun. . ein Schlofi im obera Italien habe blofs wegen der juhrlich dort einlchlagonden Gewitter verlallen werden mallon.

A. 


\section{[ $\quad 118$ ]}

bei der Reduction des Hornfilbers zu thun. Aber es wundert mich, lafs man in England bei Gelegenheit der Herfchelfcben Beubachtungen uber die verfchiedene Würme des furbigen Lichts, der Scheelifchen Verluche über Redluction des flurnlithers durch tas gehrorhene Lirlit, (Scheele's Schrifsen, gaf. von Hermbfräd, l. Tb., S. 144,) und der Sennebierfchen Verfuche mit Pflanzen fich nicht erinnert hat; jener reducirte Hurnfiber, defer weilse Pflanzen zuerft durch den violetten Stralıl. Strablendes Liclit und frrahlende Wärme, beide einander entgegengeletzt, werilen im Prisma getrennt; frrahlende Warme ift nur reflexilsel, nicht brechbar; der kältefte Strahl, (der violette,) der nach dem weif,nen die ftärkfte Lichtwirkung übt, (gegen das lalzigfaure S.lber.) ift der gebrochenfte odcr brechbartte, wie man es nennen will, und der wärmfte Strahl, der rothe, ter reflexibel\{te, (Ann. der Phyjik, V, S. เ Jo u. f.)

Meine Verfuche, (Annalen der Phyfik, V, 73 u. f.,) macuten es zwar univahricl:einlich, dafs die Electricität die Urfarhe der Confruction nach drei Dimenfionen der Kryfralliation fey, aber ob fie nicht manche regelmärsige Billungen befonders in organifchen Kürpern erklïrt, mü̈chte ich falt behaupten. Noch mag ich es nicht auf fo allgemeine Frfcheinungeu, wie z. B. die Winkel, uuter denen die Aofte der Bäıme anfchiefsen, ausdelınen; aber welche Aehnlichkeıt zwifchen den regelmäfsig unregelmälsigen, grofsten theils fecbsitrahligeu Figuren 


\section{[ 119$]$}

anf der Haut einiger Thiere, z. B. des Oftracion trigarier unci cornytus, der tefuclo geometrica, und den sraubfiguren. Beide bilden fich auf fchlechren Leitern, dort horpähnlich; beile baben zivar häufig fechs Strahlen, aber gar keine regelmälsigen Kryftallen-Winkel, keine geradẹn Kiryftallen-Linien; beide zeigen oft fünf, oft Geben Strahlen, wo fie einander hefchrïnken; eutlich zeichnete felbft die Electricilät folche Figuren auf die Oherhaut der beiden erfcluagenen Soldaten, (fiehe Theden's Erfahrungen, I. B.,) und noch neulich auf die Haut der in Harburg Erfchlagenea, (Hamburger Correfpondent , Soo.) Auch die electrifchen Fettzellen les gymnotus electricus find, $\mathrm{Vaffalli}$ zufolge, (Journ. de $P$ h), fique, T. VI,) fecliseckig, und wahrIcheinlich hat doch dies einen andern Grund, als das Z.erfallew vieler Foffilien in fechsfeitige Sterne. (Brïckmann über diefe Foffilien in Crell's Ann., 1794 , II. B., S. 498. ) 